
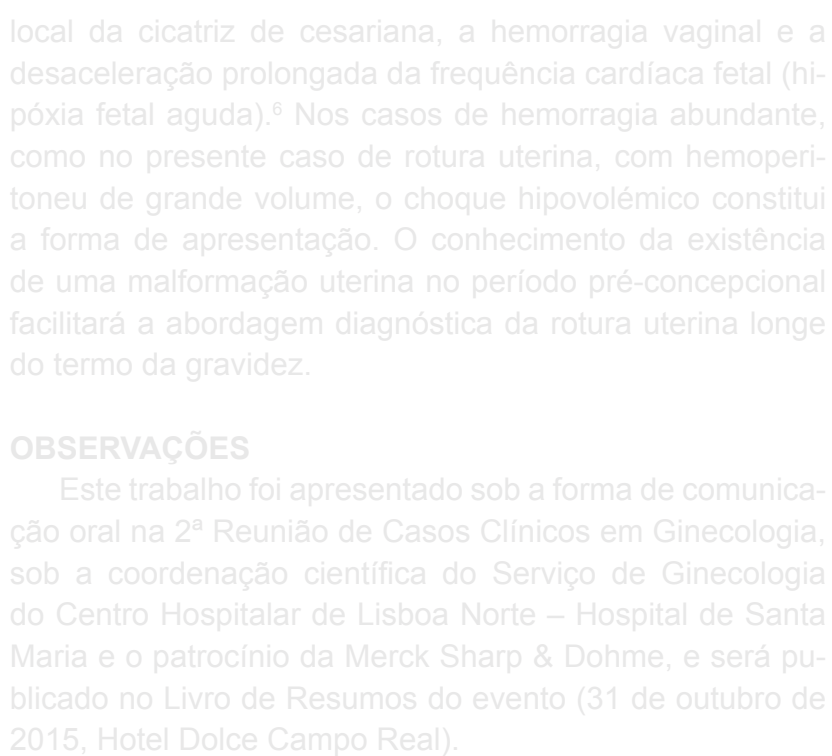

\title{
Sulco Perineal: Uma Anomalia Congénita Rara
}

\section{Perineal Groove: A Rare Congenital Anomaly}

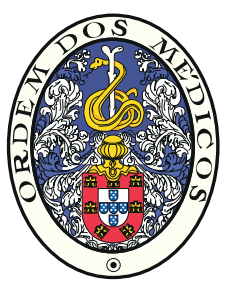

\author{
Manuel BARBOSA $\rrbracket^{1}$, Nuno ALVES ${ }^{1}$, Natacha FONTES ${ }^{2}$ \\ Acta Med Port 2016 Oct;29(10):xxx-xxx - http://dx.doi.org/10.20344/amp.7645
}

\section{RESUMO}

O sulco perineal é uma malformação congénita ano-retal rara, com incidência não determinada. É quase exclusiva do sexo feminino e ainda é incerta qual a sua origem embriológica. Descrevemos o caso de um recém-nascido do sexo feminino que teve alta do Berçário sem intercorrências ou alterações identificadas. Na primeira consulta na unidade de saúde familiar identificámos um sulco de base mucosa estendendo-se da comissura vaginal posterior ao ânus. Com este caso clínico pretendemos salientar a raridade do sulco perineal e a importância de uma anamnese e exame físicos cuidados aos recém-nascidos.

Palavras-chave: Períneo/anomalias congénitas; Recém-Nascido.

\section{ABSTRACT}

Perineal groove is a rare congenital anorectal malformation, with incidence yet undetermined. It is almost exclusive to the female newborn and its embryogenic origin remains uncertain. We present a case-report of a newborn girl that was discharged from the nursery without complications. At her first appointment at primary care we noted a wet sulcus connecting the posterior vaginal commissure

1. USF Caravela. Unidade Local de Saúde de Matosinhos. Matosinhos. Portugal.

2. Serviço de Neonatologia. Hospital de Pedro Hispano. Unidade Local de Saúde de Matosinhos. Matosinhos. Portugal.

$\triangle$ Autor correspondente: Manuel Barbosa. manuelbgbarbosa@gmail.com

Recebido: 21 de março de 2016 - Aceite: 05 de julho de 2016 | Copyright @ Ordem dos Médicos 2016 
and the anus. This case report emphasizes the rarity of the perineal groove and the importance of a good quality history and physical examination at primary care.

Keywords: Infant, Newborn; Perineum/abnormalities.

\section{INTRODUÇÃO}

O sulco perineal (perineal groove) é uma malformação ano-retal congénita que se caracteriza por um sulco não doloroso, de comprimento e profundidade variáveis, revestido de mucosa e localizado na linha média do períneo, desde o fórnix da vagina até ao ânus. ${ }^{1} \mathrm{~A}$ sua incidência e etiologia são ainda desconhecidas..$^{2-4} \mathrm{O}$ seu diagnóstico é essencialmente clínico e a sua evolução favorável com epitelização espontânea na maioria das vezes. ${ }^{3,5-7} \mathrm{O}$ tratamento cirúrgico pode ser ponderado em alguns casos particulares ${ }^{4,7} \mathrm{~A}$ importância do sulco perineal reside na necessidade dos clínicos estarem atentos para a existência desta entidade, uma vez que pode ser confundida com uma variedade de diagnósticos diferenciais desde eritema da fralda a abuso sexual.

\section{CASO CLÍNICO}

Recém-nascido do sexo feminino, filha de pais saudáveis não consanguíneos. Foi uma primeira gestação, espontânea, única, vigiada, sem intercorrências. Parto eutócico em meio hospitalar, induzido às 41 semanas e um dia. Boa adaptação do recém-nascido à vida extrauterina e antropometria adequada à idade gestacional. Não foram descritas alterações relevantes ao exame objetivo, tendo tido alta do berçário ao terceiro dia de vida, sem intercorrências, orientada para o médico assistente.

Compareceu à primeira consulta de Saúde Infantil e Juvenil na unidade de saúde familiar com uma semana de vida. Na entrevista clínica os pais não referiram nenhum sintoma específico, relatando micções e dejeções de características normais e ausência de queixas álgicas associadas à defecação. Ao exame objetivo identificámos uma

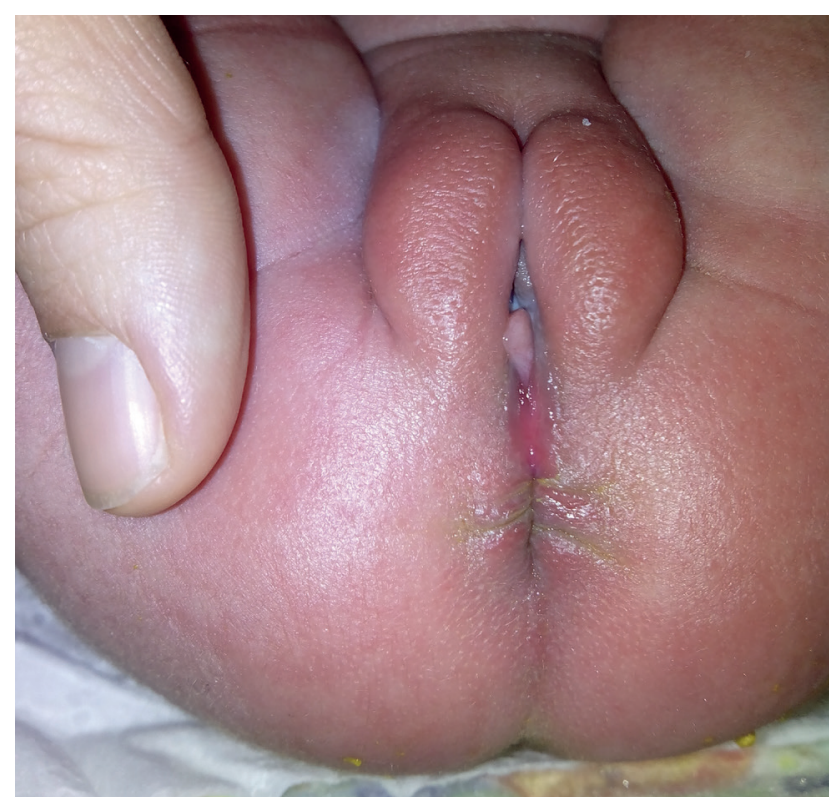

Figura 1 - Sulco perineal em recém-nascido do sexo feminino com uma semana de vida comissura vaginal posterior não encerrada, que se estendia até à face anterior do ânus num sulco de base 'húmida' (Fig.s 1 e 2). A inspeção da região vulvar era normal, o ânus bem posicionado, e não havia alterações no exame da coluna ou no exame neurológico. Sem outras alterações de relevo no exame físico, pelo que foi feito o diagnóstico clínico de sulco perineal.

A criança manteve o seguimento regular em consultas nos Cuidados de Saúde Primários de acordo com o Programa Nacional de Saúde Infantil e Juvenil, sem intercorrências.

Após seis meses o sulco encerrou espontaneamente.

\section{DISCUSSÃO}

O sulco perineal (perineal groove) é uma malformação congénita rara, desconhecendo-se a sua incidência real. Existe pouca literatura publicada sobre este tema, não havendo publicações científicas portuguesas com o termo clinico (o termo utilizado numa publicação em português do Brasil foi 'calha perineal'), pelo que os autores propõem a utilização da designação de sulco ou fenda perineal. Ocorre maioritariamente no sexo feminino, com apenas um caso descrito no sexo masculino. ${ }^{2}$

Embora a sua patogénese se mantenha incerta, o sulco perineal pode resultar de um desenvolvimento anormal da cloaca embriogénica, da falência da fusão da rafe perineal ou de um defeito no desenvolvimento do septo uroanal. ${ }^{3}$ Histologicamente observa-se pele modificada e ausência de pelo e anexos, semelhante às estruturas das pregas genitais médias. ${ }^{4}$

O diagnóstico de sulco perineal é essencialmente

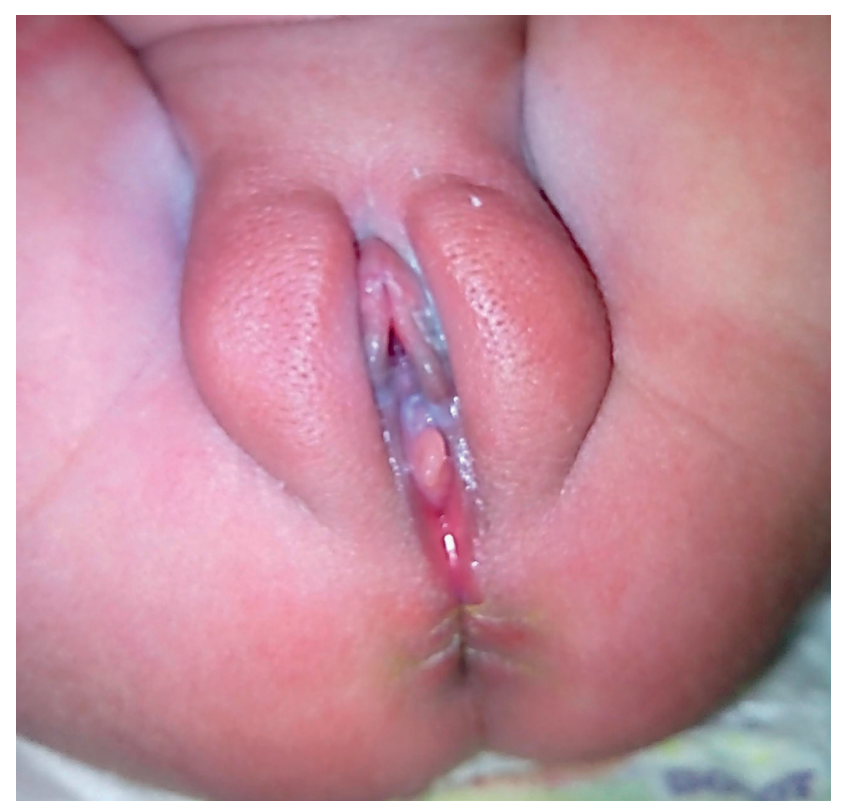

Figura 2 - Comissura vaginal posterior não encerrada, estendendo-se até à face anterior do ânus num sulco de base 'húmida' 
clínico, sendo a chave o exame minucioso da zona perineal numa posição de flexão e abdução das coxas sobre o abdómen. É habitualmente descrito como um sulco ou fenda de base 'húmida', devido à presença de uma camada mucosa que se estende da comissura posterior da vagina até à face anterior do ânus. Pode ser confundido com hemangioma ulcerado, dermatite irritativa, infeção, líquen escleroso, protrusão piramidal perianal, trauma ou abuso sexual, dificultando o diagnóstico. . $, 6,8^{-}$

A maioria dos casos de sulco perineal não se associa a outras malformações, não havendo necessidade de realizar estudos imagiológicos, biópsia ou outros exames complementares invasivos para fazer o diagnóstico e tranquilizar os pais. ${ }^{4,6}$ Existem apenas três casos descritos com alterações congénitas coexistentes: uma criança com hipospádias e escroto bífido, uma com ânus ectópico e uma com anomalia não especificada do trato urinário. ${ }^{9}$

Enquanto a maioria das lesões se mantêm assintomáticas, complicações podem incluir obstipação, defecação dolorosa, fissura anal, prurido, descarga mucosa persistente, infeções do trato urinário, infeções cutâneas e, na vida adulta, quadros de vulvodinia/dispaneuria. ${ }^{10,11}$

O sulco perineal tem na generalidade uma evolução favorável, auto-resolutiva, sendo o seu decurso natural a epitelização espontânea ao fim de meses ou anos. , $^{3,9}$ Normalmente não requer tratamento específico. O tratamento cirúrgico ativo poderá estar indicado por razões estéticas, por persistência de sintomas como ardor, infeções ou drenagem mucosa..$^{3-5,7}$ No caso de se optar por este tratamento, recomenda-se que apenas se realize após os dois anos de idade, quando já foi ultrapassado o potencial para resolução espontânea. ${ }^{10}$

A importância do sulco perineal reside na necessidade dos clínicos estarem atentos para a existência desta entidade pouco descrita, uma vez que pode ser confundida com uma variedade de diagnósticos diferenciais. Existem relatos de tratamentos desapropriados (cremes barreira, anti-fúngicos, laser) e orientações erróneas por suspeita de abuso sexual (Serviço Social, Medicina Legal), com todas as implicações que estas medidas têm para a família e a criança. ${ }^{9}$

\section{CONCLUSÃO}

Dada a raridade de publicações deste distúrbio, ressalva-se a importância deste caso clínico. Não se conhecendo ao certo a sua incidência e etiologia, é fundamental os clínicos estarem alerta para a existência desta entidade e divulgarem os casos observados, para que se consiga estabelecer a verdadeira incidência, sendo provavelmente mais elevada do que se estima. Salientamos a necessidade de uma história clínica e exame físico cuidados nas consultas de Saúde Infantil e Juvenil. Trata-se de uma patologia normalmente benigna e de resolução espontânea. No entanto, o seu diagnóstico diferencial inclui outras entidades que é necessário excluir, para evitarmos investigações e tratamentos desnecessários, podermos tranquilizar os cuidadores e minorar gastos dispensáveis na saúde.

\section{PROTECÇÃO DE PESSOAS E ANIMAIS}

Os autores declaram que os procedimentos seguidos estavam de acordo com os regulamentos estabelecidos pelos responsáveis da Comissão de Investigação Clínica e Ética e de acordo com a Declaração de Helsínquia da Associação Médica Mundial.

\section{CONFIDENCIALIDADE DOS DADOS}

Os autores declaram ter seguido os protocolos do seu centro de trabalho acerca da publicação de dados.

\section{CONFLITOS DE INTERESSE}

Os autores declaram não terem qualquer conflito de interesse relativamente ao presente artigo.

\section{FONTES DE FINANCIAMENTO}

Não existiram subsídios ou bolsas que tenham contribuído para a realização do trabalho.

\section{REFERÊNCIAS}

1. Stephens FD. The female anus, perineum and vestibule. Embryogenesis and deformities. Aust N Z J Obstet Gynaecol. 1968;8:55-73.

2. Chatterjee SK, Chatterjee US, Chatterjee U. Perineal groove with penoscrotal hypospadias. Pediatr Surg Int. 2003;19:554-6.

3. Sekaran P, Shawis R. Perineal groove: a rare congenital abnormality of failure of fusion of the perineal raphe and discussion of its embryological origin. Clin Anat. 2009;22:823-5.

4. Pastene SC, Rojas MF. Surco perineal en ginecología infantil: reporte de 2 casos clínicos. Rev Chil Pediatr. 2014;85:486-90.

5. Verma SB, Wollina U. Perineal groove-a case report. Pediatr Dermatol. 2010;27:626-7.

6. Diaz L, Levy ML, Kalajian A, Metry D. Perineal groove: a report of 2 cases. JAMA Dermatol. 2014;150:101-2.
7. Mullassery D, Turnock R, Kokai G. Perineal groove. J Pediatr Surg. 2006;41:e41-3.

8. Carrera Polanco M. Perineal groove, o cómo un hallazgo pequeño puede convertirse en un problema grande. Rev Pediatr Aten Primaria. 2012;14:323-6.

9. Hunt L, Srinivas G. Visual diagnosis: newborn with a perineal lesion. Pediatr Rev. 2016;37:e1-3. doi:

10. Esposito C, Giurin I, Savanelli A, Alicchio F, Settimi A. Current trends in the management of pediatric patients with perineal groove. J Pediatr Adolesc Gynecol. 2011;24:263-5.

11. Jesus LE. Calha mucosa perineal (perineal groove): variante clinica de malformacao anoretal. Rev Bras Coloproct. 2004;24:308-10. 